\title{
Research on Governance Structure of Big Data of Civil Aviation
}

\author{
Jing Xiong1,2, Gang Yư ${ }^{3}$, Xu Zhang1 \\ ${ }^{1}$ College of Air Transportation, Shanghai University of Engineering Science, Shanghai, China \\ ${ }^{2}$ College of Electronics and Information Engineering, Tongji University, Shanghai, China \\ ${ }^{3}$ SILC Business School, Shanghai University, Shanghai, China \\ Email: crystal_420@126.com
}

How to cite this paper: Xiong, J., Yu, G. and Zhang, X. (2017) Research on Governance Structure of Big Data of Civil Aviation. Journal of Computer and Communications, 5, 112-118. https://doi.org/10.4236/jcc.2017.55009

Received: February 7, 2017

Accepted: March 28, 2017

Published: March 31, 2017

Copyright $(9) 2017$ by authors and Scientific Research Publishing Inc. This work is licensed under the Creative Commons Attribution International License (CC BY 4.0).

http://creativecommons.org/licenses/by/4.0/

\begin{abstract}
Facing with the enormous data scale of the civil aviation industry, the vital issue that enterprises must consider is how to manage and make use of data to play its value. In this study, the content of the governance of big data of civil aviation is analyzed and this paper put forward the specific governance of big data resources of civil aviation to provide relevant support of the governance of big data resources of civil aviation.
\end{abstract}

\section{Keywords}

Civil Aviation, Big Data, Governance Structure

\section{Introduction}

The 13th Five Year Plan is a critical period for China to build the overall well-off society. The trends like diversity and popularity are becoming obvious in Chinese civil aviation and rapid growth is still the basic phase feature. Civil aviation development is ushered in a new historical opportunity [1]. The informatization of civil aviation is popularized in a certain extent. A large number of civil aviation agencies and practitioners produce abundant industry-specific data, but these data is distributed in different institutions of the civil aviation industry and the heterogeneous data is severe. $75 \%$ of the huge amount of existing data now reserved in civil aviation enterprises is unstructured data, including various text, audio, images, videos, social relations, space trace, etc. The value of big data of civil aviation puts it in danger of privacy and security problem. The governance of big data of civil aviation acts a crucial role in managing and protecting organizing data in linking the department, process, people and the other elements of the organization with the whole life cycle [2]. 
The main contents of the research on governance structure of big data of civil aviation are as follows:

1) Civil aviation information system has been widely used after years of development, but the research of data management is mainly focused on the analysis of structured data, the data structure of each civil aviation system is different, in the field of civil aviation there is no effective data sharing mechanism [3] [4]. 2) Big data management and sharing mechanism research focused on the policy level, there is lack of research on governance structure of big data of civil aviation [5] [6]. 3) According to the survey of the literature, the study of the governance structure of big data of civil aviation is still in its infancy.

\section{Governance Content Analysis of Big Data of Civil Aviation}

Three parts of big data of civil aviation governance are framework, Data management module and Data operation and maintenance. By framework, we establish management method and develop work flow and define roles and responsibility. Data management module mainly includes data standard management, metadata management, data quality management, data asset management, data security management. With the collaboration of each module, the data from data platform will be ensured to be consistent, safe and effective. Data operation and maintenance which is throughout the whole process of data management system make the thought of operation and maintenance on platform come true. Governance collectivity content of civil aviation of big data is shown in Figure 1.

\subsection{Standard of Big Data of Civil Aviation}

By developing unified data standards and combined with institutional constraints, system control, etc. the integrity, effectiveness, consistency, standardization, openness and sharing management of the data from the big data platform can be realized and to improve the standard of data management in the big

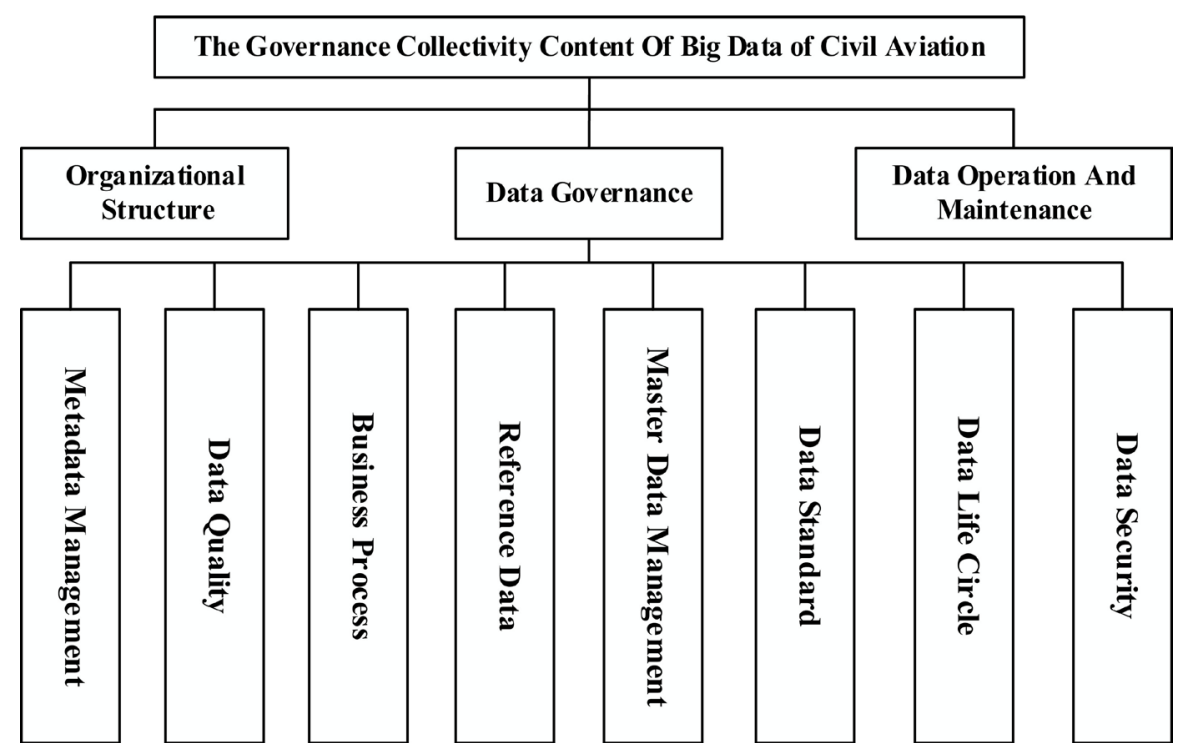

Figure 1. Governance collectivity content of civil aviation of big data. 
data platform of civil aviation, which mainly includes both basic and industry data standards.

\subsection{Metadata Management of Big Data of Civil Aviation}

In combining with organizational information form of metadata and to specific describe all forms of digital objects in civil aviation. To define the enterprise's metadata management in prospect, target, demands, constraints, strategies and so on. To confirm the roadmap of the maturity of metadata management and target accomplishment and to complete the structure of fundamental ontology, domain ontology, task ontology and application ontology and to ensure the security strategies, version control and subscribe metadata to push of the metadata management according to the present and future demands of firm itself.

\subsection{Technical Structure of the Governance of Big Data of Civil Aviation}

To provide guidance for business requirement analysis, system function design, research and development of technical framework, service pattern innovation and value realization, which mainly include data storage, data warehouse, metadata, master data, etc.

\subsection{Definition and Description of Related Business of Civil Aviation}

The key to fulfilling the plan of data governance ideally is how to precisely define and describe business problems. By comprehensively weighing the degree of urgency and the value brought by data governance in civil aviation, and give data governance priority to the top-ranked problems or realms. This will gain full support from both business function and IT department to make sure that the data governance plan will succeed. After the original scope of data governance is settled, the specific work of data governance will be carried out and will be considered to extend to other realms if it worked.

\subsection{Master Data Management (MDM) of Big Data of Civil Aviation}

To meet the demands and targets of master data management, we do the research by spotting MDM objects [7], confirming master data owners, establishing MDM organizations, regulating MDM process, unifying master data standards, analyzing and building the position and integrated frame requirements of MDM system. In addition, a MDM system in civil aviation will be researched and planned.

\subsection{Quality Management of Big Data of Civil Aviation}

On the platform of big data in civil aviation, data quality provides it with clean and explicit-structured data, which is vital premise to develop data products and provide data services and bring value to big data on the platform. And also the key factor to the data assets management of civil aviation.

It mainly focuses on governing the data classification quality measures, data 
quality check definitions, data quality check implementation, data quality check analysis, data quality issues management, data quality management knowledge and so on.

\subsection{Sharing System of Big Data of Civil Aviation}

According to the characteristics of data, using distributed information sharing based on agent structure and solving the problem of information synergy technology by XML-agent technique [8]. The whole system can be divided into the master data base, data engine, directory information center, information node, agent access, etc.

\subsection{Security System of the Governance of Big Data of Civil Aviation}

Data security policy and security policy measures are established to provide effective approval, authorization, access and audit [9]. Achieving detailed implementation plan of sensitive data access and realizing privacy protection technology and management action of customer privacy protection. With enhancing the technical safeguard of data security.

\section{Governance Structure of Big Data of Civil Aviation}

\subsection{Governance Structure}

Through the exploration, cleaning, integration, monitoring and information mining of civil aviation business master data, the master data quality will be improved. With the combination of data management and civil aviation enterprise organization, the data integration and mining application will be provided a strong guarantee. Specific governance framework is shown in Figure 2.

\subsection{Key Technologies}

1) Metadata integration architecture based on CWM model driven

It mainly focuses on metadata integration architecture based on common warehouse met a model. The architecture uses the MOF model based on formal and independent of platform specific implementation, uses UML formal language to describe the information structure, constructs exchange metadata based on the CWM model which is public and outside [10], achieves mutual understanding between models, solves the problems between the metadata translation model, greatly reduces the metadata bridge, so as to improve the enterprise data integration ROI.

2) Dynamic metadata cluster management based on consistent Hash structure

It mainly focuses on the dynamic metadata cluster management scheme based on the consistency of Hash, which can realize the efficient management and flexible expansion of the cluster metadata in the mass data storage system, and reduce the data migration cost. Through adding virtual metadata server structure to the consistency in Hash structure and extending the single and unbalanced mapping which is from metadata to the metadata server to the balanced 


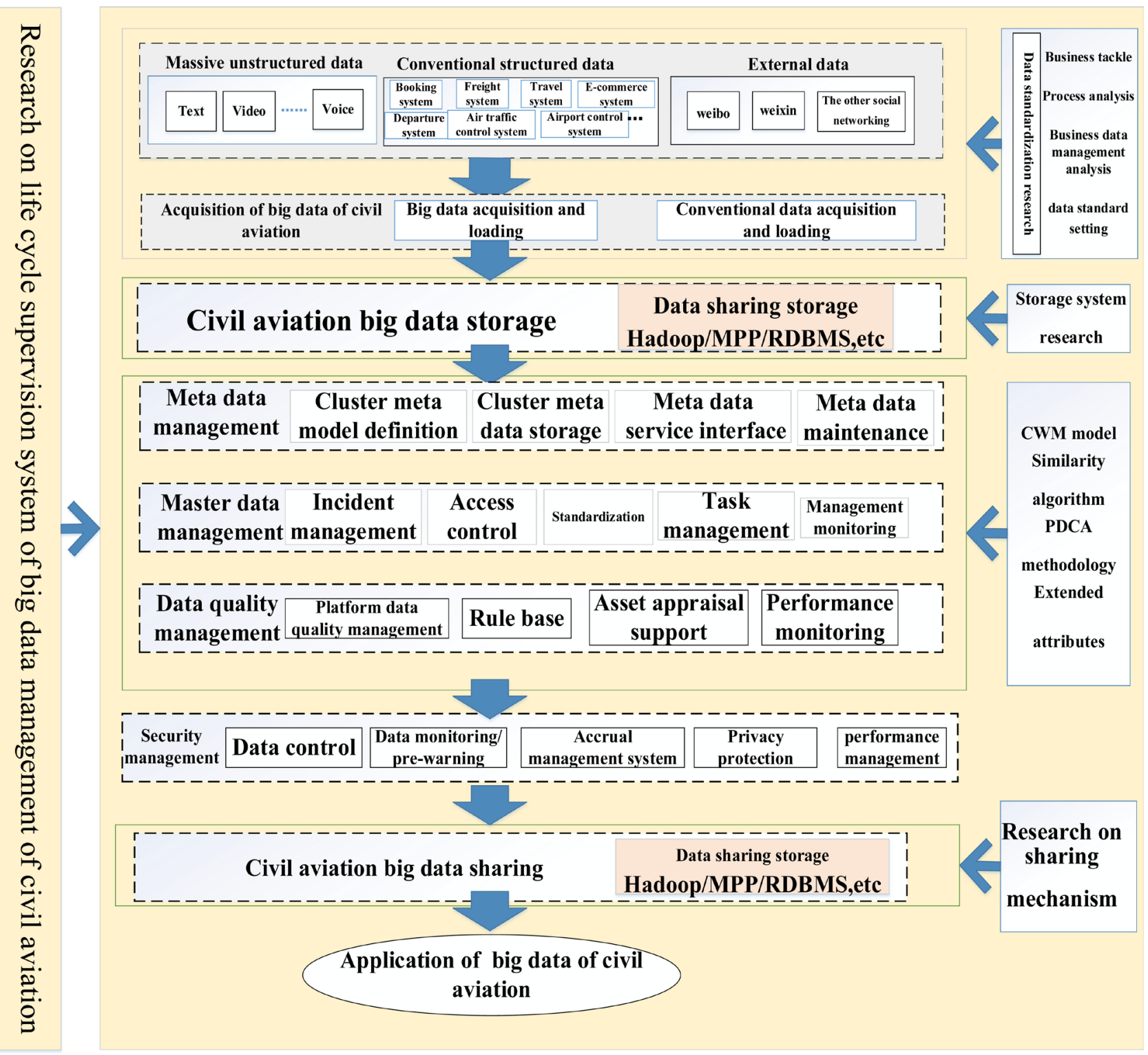

Figure 2. Governance structure of big data of civil aviation.

mapping which is from metadata to virtual metadata server and metadata server, it can improve the whole service metadata server cluster load balancing work.

3) Establishing formal reasoning framework of metadata

In the process of establishing metadata based on the common warehouse model (CWM) [11], different experiences of participating in the establishment of metadata and different perspectives of the data description inevitably leads to the problems of conflict and redundancy of metadata. However, the graphical features of CWM make it lack of precise semantics. In the metadata integration architecture in the process of research, this project focuses on how to reasoning on CWM to automatically detect these problems, and studies the method of making use of the CWM model and metadata and reasoning, and we can enables it to support the ability of metadata version, so as to reasoning inconsistent problems caused by evolution, then inference engine is used to detect the incon- 
sistent information.

4) Quality management of big data of civil aviation based on PDCA methodology

Through the cycle process of the planning, implementation, inspection, analysis and adjustment, this study focuses on quality management of big data of civil aviation based on PDCA method.

5) Maturity evaluation of governance structure of big data of civil aviation based on CMM

Based on the analysis of the classification method of the capability maturity model (CMM) [12], this study evaluates the maturity of governance of big data of civil aviation data, and puts forward the optimization strategy of the governance process according to the evaluation results.

\section{Summary}

By developing and publishing unified data standards and combined with institutional constraints, system control, etc., the integrity, effectiveness, consistency, standardization, openness and sharing management of the data from the big data platform is realized and the standard of data management in the big data platform of civil aviation is improved.

Through establishing the complete governance system of civil aviation big data and improving structure, quality, safety compliance, etc., significant promotion will be occurred in the service innovation and value creation of civil aviation big data.

\section{References}

[1] Tang, H.W. (2015) Data Integration Analysis of Civil Aviation Information. Electronic Technology and Software Engineering, 5, 55-58.

[2] Wang, W. (2013) Research on Data Management of Commercial Banks in the Era of Big Data. Financial Computer of China, 7, 36-38.

[3] Wang, Z. and Yin, J.L. (2014) Research on the System of Personal Data Privacy Governance in the Context of Big Data Based on the Perspective of Stakeholders. Technoeconomics \& Management Research, 8, 71-74.

[4] Zhang, W.X., Xiang, L.Z. and Wang, X.F. (2014) Big Data Partition Management Model and Its Application. Journal of Harbin Engineering University, 3, 353-360.

[5] Wei, C.H. (2016) Research on Big Data Sharing. Wireless Internet Technology, 4, 84-85.

[6] Lu, W.X., Tu, Z.S. and Liang, Y. (2016) Research on Data Sharing Model Based on HBase. Computer Technology and Development, 4, 36-40.

[7] Li, X.B., Zheng, Y. and Xiong, G. (2015) Identification and Management of Master Data for Open Platform of Civil Aviation. Computer and Digital Engineering, 7, 1304-1327.

[8] Cao, G.N., Shi, C.W. and Chen, X.X. (2016) Service Oriented Cross Platform Database Data Sharing. Computer and Modernization, 1, 94-104

[9] Pang, Y.M., Li, X.D. and Ye, S.S. (2015) Research and Implementation of Cloud Data Sharing Mechanism Based on Proxy Re Encryption. Journal of Nanjing University of Science and Technology, 2, 84-88. 
[10] Y.C. Wang, Li, S.N. and Li, A.H. (2015) Research on Data Alliance-Building the Infrastructure for Global Data Sharing and Data Exchange. Information Management and Science, 3, 52-54.

[11] Yuan, M. Wang, D.D. and Zhai, H.C. (2015) Data Sharing Technology Based on Standard Data and Data Port Architecture. Journal of Northeast Petroleum University, 8,103-108.

[12] Chen, G.M. (2016) Research on Big Data Governance Model and Governance Maturity Evaluation. Technology and Innovation, 9, 6-7.

Submit or recommend next manuscript to SCIRP and we will provide best service for you:

Accepting pre-submission inquiries through Email, Facebook, LinkedIn, Twitter, etc. A wide selection of journals (inclusive of 9 subjects, more than 200 journals)

Providing 24-hour high-quality service

User-friendly online submission system

Fair and swift peer-review system

Efficient typesetting and proofreading procedure

Display of the result of downloads and visits, as well as the number of cited articles Maximum dissemination of your research work

Submit your manuscript at: http://papersubmission.scirp.org/

Or contact jec@scirp.org 